Bacharach, V.R., \& Baumeister, A.A. (1998). Direct and indirect effects of maternal intelligence, maternal age, income, and home environment on intelligence of preterm, low-birth-weight children. Journal of Applied Developmental Psychology, 19(3): 361-375. (July-Sept 1998) Published by Elsevier (ISSN: 1873-7900). DOI:10.1016/S0193-3973(99)80045-8

\title{
Direct and Indirect Effects of Maternal Intelligence, Maternal Age, Income, and Home Environment on Intelligence of Preterm, Low-Birth-Weight Children
}

Verne R. Bacharach and Alfred A. Baumeister

\begin{abstract}
Low birth weight (LBW) infants are at elevated risk for adverse developmental outcomes, including impaired cognition. From a public health perspective, interventions designed primarily to prevent and/or secondarily to avert intellectual impairments could have substantial impact on social and fiscal costs associated with LBW. But LBW is a heterogenous condition correlated with demographic, biological, psychological, and social variables. In this study we examined direct and indirect effects of maternal intelligence, age, income, and home environment on 3year intelligence among premature LBW children. Hierarchical regression analyses were employed to determine the extent to which SES (measured by family income) and home environment mediate effects of maternal IQ and age on child IQ. Maternal IQ was found to have major direct and indirect consequences. Indirect effects were mediated by income and home environment. A small part of the influence of income is explained by home environment. Taken together with results of other studies, these findings suggest that standard family interventions to improve cognitive outcome for children of poor and intellectually compromised women are not likely to produce impressive results.
\end{abstract}


Preterm, low-birth-weight infants (LBW $<2500 \mathrm{~g}$ ) are at significantly elevated risk for delayed cognitive development in comparison with full-term, normal-birth-weight infants (NBW) (Baumeister \& Bacharach, 1996; Hack, Klein, \& Taylor, 1995). Furthermore within the LBW range, a weight gradient describes this relationship in that risk for cognitive delay increases as weight decreases (Breslau, et al., 1994; Escobar, Littenberg, \& Petitti, 1991). A recent population-based study has shown that for both LBW and NBW prematurity (controlling for sex, birth order, maternal age, maternal race, and maternal education) adjusted odds ratios for mental retardation were 2.8 (Mervis, Decoufle, Murphy, \& Yeargin-Allsopp, 1995). As might be expected, risk even was higher for very LBW children.

The relationship among LBW, risk profile, and behavioral outcome has long been known to be multiply and inter-generationally determined, implicating numerous distal social and more proximal familial and biological factors (Birch \& Gussow, 1970; Emanuel, Filaki, Albennan, \& Evans, 1992; Drillen, 1964; Rutter \& Madge, 1976). Over 20 years ago Hardy and Mellits (1977) listed more than 30 factors known to be associated with birthweight including behavior, medical, and economic variables. Obviously simple univariate and bivariate analyses are insufficient to capture the nature and complexity of variables that place a child at risk for LBW and that mediate the outcome (Willerman, 1979; Ramey \& MacPhee, 1986).

Epidemiological and clinical studies reveal LBW children are particularly vulnerable to socioeconomic, biological, and psychological risks that predispose all children to impaired cognitive development (Alberman, 1994). But simple extrapolation from circumstances that condition outcome for NBW children to those who are premature LBW is misleading because an important interaction involves birth weight and social circumstances. While both LBW and NBW children reared in high-risk social environments experience poorer developmental outcomes than those in more wholesome social milieus, LBW children are more greatly affected (McGauhey, Starfield, Alexander, \& Ensminger, 1991; Siegel, 1982). Moreover, the social risk profile is different for LBW children (Starfield, 1992). Heightened relative risk for LBW premature children applies not only to specific health outcomes, but to broader performance indicators such as school achievement and behavior disorders. In view of these considerations, different and more creative intervention strategies are indicated for LBW children and their families.

Maternal IQ is a major consideration in assessing developmental risks associated with LBW and what may be done to alleviate them. Using maternal education as a marker of intelligence, Wilson (1985) found among samples of monozygotic and dizygotic LBW twins, one born smaller than the other, that maternal intelligence was the strongest predictor of preschool IQ. Maternal intelligence accounted for variance otherwise due to socioeconomic factors associated with home environment. Heritage had a powerful effect that increased over time. LBW children making the greatest recovery from initial suppressing effects of prematurity are those from more advantaged families. Reared in supportive environments, most LBW infants will recover from early trauma, even those born at very LBW. This is a consideration that is too often overlooked because children are resilient, even in the face of multiple adversities. Resilience poses the questions as to which aspects of the familial-social-economic context contribute to development of LBW children, which children are most susceptible, and where is it possible to design tailored intervenetions. Some predisposing variables cannot be altered (e.g., low maternal intelligence), while some may be (e.g., events associated with low income). 
Hierarchical analyses of cognitive development among LBW children indicate causally prior effects of maternal intelligence are both direct and indirect. Some portion of the maternal IQ effect is mediated by experiences in the home environment, particularly those aspects that are cognitively enriching (Baumeister \& Bacharach, 1996; Bradley, Caldwell, \& Rock, 1990; Bradley, Whiteside, Caldwell, et al., 1993). According to Bradley, Whiteside, and Caldwell, et al. (1993) the respective contributions of maternal IQ and home environment to child IQ may also be associated with maternal age.

Although the correlation between parental and child IQ among LBW children appears to be partly dependent on the child's experiences within the home, there is reason to be cautious about overstating the case for improving the home environment. First, efforts to alter the developmental trajectories by home intervention have been less than impressive. Second, the correlation between child intelligence and home environment also has a genetic component in that more competent parents may provide more stimulating and enriching experiences (Plomin \& Bergeman, 1991).

We assume that a number of variables mediate effects of maternal IQ on cognitive development of LBW children. This assumption is difficult to test because conditions that predispose these children to developmental disabilities covary. Multicollinearity is to be expected in generating models for predicting intellectual performance among premature LBW children. Many predictor variables will have low tolerance. For this reason it is essential to employ hierarchical analyses in situations such where suspected risk and mediating variables are implicated in the outcome. For example, family income, maternal IQ, and maternal age are correlated, and all are related to developmental disabilities. There is also evidence that low maternal IQ and poverty exert independent detrimental effects on child IQ (Feldman \& Walton-Allen, 1997). Descriptive epidemiology or demographic studies have identified many possible causes of disease processes such as prematurity or LBW. Descriptive studies are necessary, but it is analytical epidemiology that will reveal key causes.

One approach to disentangling this complex web of associations is to employ hierarchical regression procedures incorporating variables known to mediate the connection between maternal IQ and child cognitive development. Given collinearity among predisposing variables, it is important to employ hierarchical models to identify direct and mediated effects and to estimate their relative contributions to child IQ.

Several multivariate comprehensive frameworks have been proposed that link developmental outcomes to predisposing and systemic variables in an effort to describe paradigms for unraveling the relationships among variables at different levels, from proximal to more distal (e.g., Baumeister, Kupstas, \& Woodley-Zanthos, 1993; Brofenbrenner, 1977; Garbino, 1991; Sameroff, 1983). Each conceptualizes compromised cognitive outcome in terms of multiple risks, occurring over time, and in a hierarchical manner. These models can thus identify points, either at individual or systemic levels, where interventions might be most efficacious and/or cost-effective. Inclusive conceptualizations delineate the various ways that cognitive development among preterm LBW infants is influenced by psychological, socioeconomic, and biological threats, including diminished maternal IQ. Although differing in detail and emphasis, these systems models share the common perspective of contextualism: the child is regarded as a biological entity in interaction and transaction with a network of family, community, service, social, economic, and political systems. 
Studies have consistently shown that, aside from maternal intelligence, certain predisposing variables influence cognitive development among LBW children. Intellectual development is related to maternal age (Liaw \& Brooks-Gunn, 1993). Poverty, as measured by family income, also influences cognitive outcome (Duncan, Brooks-Gunn, \& Klebanov, 1994; Thompson, Goldstein, Oehler, Gustafson, Catlett, \& Brazy, 1994). Birthweight effects are exacerbated by absence of the father (Ricciute \& Scarr, 1990). The relationship between resource variables, such as quality of the home environment, and cognitive development have been documented in other studies (Bradley \& Casey, 1992; Lee \& Barratt, 1993; Liaw \& Brooks-Gunn, 1993). These variables are not independent of one another, and their relative and independent contributions to cognitive development among LBW children are uncertain.

Aside from SES, maternal education is the most frequent variable examined in the literature regarding the connection between LBW and cognitive outcome. The strongest predictor of child IQ-maternal intelligence (Ramey \& Ramey, 1992)-typically is not included in hierarchial multivariate analyses predicting cognitive development among premature LBW children. Although, as noted, a common procedure is to employ education as a proxy, in a previous study involving the LBW cohort included in the present analysis Baumeister and Bacharach (1996) found that the partial correlation for maternal education and child IQ, with maternal IQ controlled, was .09. Controlling for maternal education, the corresponding correlation for maternal IQ was .43.

Influence of maternal IQ should be mediated by predisposing variables such as maternal age at parturition, the effects of which are, in turn, conditioned by income or SES. The impact of income or SES should be moderated by family influences such as the home environment, while resource variables (e.g., income) may have a direct effect on cognitive growth among at-risk LBW children. The purpose of this investigation is to test these hypotheses within a hierarchical regression model.

\section{METHOD}

In the present investigation we used public domain, archival data from a large-scale longitudinal study of cognitive development among preterm (37 weeks gestational age or less), LBW (2,500 grams or less) children!. The goal was to explore the pattern of correlations of maternal IQ, maternal age, family income, and quality of the home environment on intellectual growth of these at-risk children. This longitudinal clinical-trial study is known as the Infant Health and Development Program (IHDP) (1990).

\section{Infant Health and Development Program (IHDP)}

The IHDP was a multi-site randomized clinical trial to evaluate the influence of early educational and family intervention on intellectual development of preterm, LBW infants. Infants were randomly assigned to treatment or follow-up (control) groups. Children in the treatment condition received a package of services of which free, intensive day care was the most salient and intense component. Those in the follow-up group were provided medical examinations, but otherwise did not receive any of the interventions. Data were collected on a large number of variables including maternal IQ, maternal age at parturition, family income, and quality of the home environment. (Given that assessment of maternal 
IQ was with the PPVT-R, it is perhaps more technically accurate to refer to this measurement as an index of maternal verbal competence. With that caveat in mind, however, we shall continue to refer to maternal IQ or intelligence.) Details of the IHDP can be found in numerous publications (e.g., The Infant Health and Development Program, 1990; BrooksGunn, McCarton, Casey, et al., 1994; Gross, Spiker, \& Haynes, 1997; McCormick, McCarton, Tonascia, \& Brooks-Gunn, 1993).

\section{Participants}

This analysis included 453 children assigned to the follow-up group and for whom there was a complete set of data for each of the following predictor variables: (a) maternal age at childbirth; (b) family income determined when the children were 1 year of age2; (c) total scores on the Infant-Toddler version of the Home Observation for Measurement of the Home Environment (HOME) inventory (Caldwell \& Bradley, 1984), assessed when the children were 12 months of age; and (d) maternal IQ. Thirty-six month Stanford-Binet IQ scores were available for children.

Approximately $52 \%$ of the mothers in the sample were Black, $9 \%$ were Hispanic, and $39 \%$ were categorized as "White, Asian, or Other". Although the study sample included mothers from a wide range of socioeconomic backgrounds, at the time of the child's birth the mothers as a group were poorly educated (34\% had not completed high school). Mean family income was $\$ 21,650$ with sufficient range to enable determination of mediated and direct contributions of this variable. Birth weights of children ranged from $540 \mathrm{~g}$ to $2500 \mathrm{~g}$ $(M=1797 \mathrm{~g} ; S D=458 \mathrm{~g})$. Fifty-one percent were female.

\section{Assessment}

Authors of the IHDP used the Peabody Picture Vocabulary Test-Revised (PPVT -R) to measure maternal IQ (Brooks-Gunn \& Benasich, 1992). The PPVT-R was administered to participating mothers when their children were 18 months of age. Assessments were done at research site clinics by staff masked to condition. The HOME inventory was administered by other trained assessors also unaware of condition. Child IQs at 36 months of age were obtained from the Stanford-Binet Intelligence Scale Form L-M, 3rd edition by psychologists not involved in any of the previous evaluations. IQ scores were corrected for gestational age.

\section{Analytic Strategy}

Hierarchical regression analyses were conducted to estimate the direct and indirect effects of the predictor variables on child IQ (Alwin \& Hauser, 1975; Cohen \& Cohen, 1983). Predictor variables selected were (1) maternal IQ, (2) maternal age at parturition, (3) family income, and (4) quality of the home environment. As indicated previously, these variables have been implicated in determination of child IQ, including premature LBW children. With the exception of maternal IQ, the remaining variables are potentially modifiable to some extent. Maternal IQ was included because it is, by far, the most potent predictor of child IQ. The intention was to determine how much variance remains after maternal IQ is controlled. Furthermore, the question arises as to the proportion of maternal IQ effects mediated through the remaining variables. 
Order of entry in the regression equation was determined by reference to their likely temporal occurrence along with related logical and empirical considerations. That is, young mothers tend to have lower incomes which, in turn, affects quality of home. With regard to the particular ordering of variables in this study there are, of course, plausible alternatives. For instance, in their multivariate analyses of the same data set Brooks-Gunn, Klebanov, \& Duncan (1996) entered (1) child health and demographic variables, (2) economic status, (3) family structure and maternal characteristics (including maternal IQ), and (4) home environment measures in that order. By the fourth step, maternal IQ did not explain any of the black-white IQ differences. It is well known that order of entry greatly influences interpretation of effects of specific variables. Brooks-Gunn, et al. (1996) did not provide an explicit rationale for their choice of model.

It might be argued that maternal age at parturition influences measured verbal intelligence because a pregnant teenager is more likely to drop out of school with the possible effect of reduced verbal skills. We believe that the weight of the evidence overwhelmingly favors the interpretation that intelligence determines length of stay in school. The case may also be made that low family income encourages early pregnancy because of increased welfare benefits. Again, a more parsimonious interpretation is that the proper sequence is Maternal Age before Family Income for the reason that income was measured when the infant was one-year of age and the outcome measure--cognitive development of the child-will be more greatly influenced by current household income then income before the woman became pregnant.

\section{RESULTS}

Summary statistical values for variables examined in this study can be found in Table 1 . Zero-order correlation coefficients among the variables in the study are presented in Table 2.

Table 1. Summary Statistical Values for Variables use in Primary Analyses

\begin{tabular}{llc}
\hline & Mean & Standard Deviation \\
\hline Child IQ & 86.58 & 19.47 \\
Maternal IQ & 82.28 & 21.71 \\
Maternal Age & 25.11 & 5.93 \\
Family Income & $21.65(\mathrm{k})$ & 16.81 \\
HOME Score & 33.97 & 6.10 \\
\hline
\end{tabular}

Table 2. Zero Order Correlation Coefficients for Variables in Model

\begin{tabular}{lcccc}
\hline & $\begin{array}{c}\text { Maternal } \\
\text { IQ }\end{array}$ & $\begin{array}{c}\text { Maternal } \\
\text { Age }\end{array}$ & $\begin{array}{c}\text { Family } \\
\text { Income }\end{array}$ & $\begin{array}{c}\text { Quality } \\
\text { of Home }\end{array}$ \\
\hline Child IQ & .53 & .26 & .52 & .46 \\
Maternal IQ & & .49 & .56 & .54 \\
Maternal Age & & & .42 & .30 \\
Family Income & & & & .44 \\
\hline
\end{tabular}

Note: $\quad p$ for all values $<.01$ 
Table 3. Regression Coefficients and Standard Errors Regressing Child IQ at 36 Months on the Independent variables by Order of Entry

\begin{tabular}{|c|c|c|c|c|}
\hline \multirow[b]{2}{*}{$\begin{array}{l}\text { Independent } \\
\text { Variables }\end{array}$} & \multicolumn{4}{|c|}{ Steps } \\
\hline & 1 & 2 & 3 & 4 \\
\hline$\overline{\text { Maternal IQ }}$ & $\begin{array}{c}.47 \\
(.04)\end{array}$ & $\begin{array}{c}.47 \\
(.04)\end{array}$ & $\begin{array}{c}.33 \\
(.04)\end{array}$ & $\begin{array}{c}.26 \\
(.05)\end{array}$ \\
\hline Maternal Age & & $\begin{array}{l}-.02 \\
(.19)\end{array}$ & $\begin{array}{l}-.24 \\
(.14)\end{array}$ & $\begin{array}{l}.24 \\
(.14)\end{array}$ \\
\hline Fumily Income & & & $\begin{array}{c}.40 \\
(.05)\end{array}$ & $\begin{array}{c}.35 \\
(.05)\end{array}$ \\
\hline Quality of Home & & & & $\begin{array}{l}.60 \\
(.14)\end{array}$ \\
\hline$R^{2}$ & $.28^{*}$ & .28 & $.36 *$ & $.38 *$ \\
\hline Constant & 47.70 & 47.97 & $\begin{array}{c}56.60 \\
F(4,448)=\end{array}$ & $\begin{array}{c}43.04 \\
p<.001\end{array}$ \\
\hline
\end{tabular}

Note: $* R^{2}$ Change $p<.001$

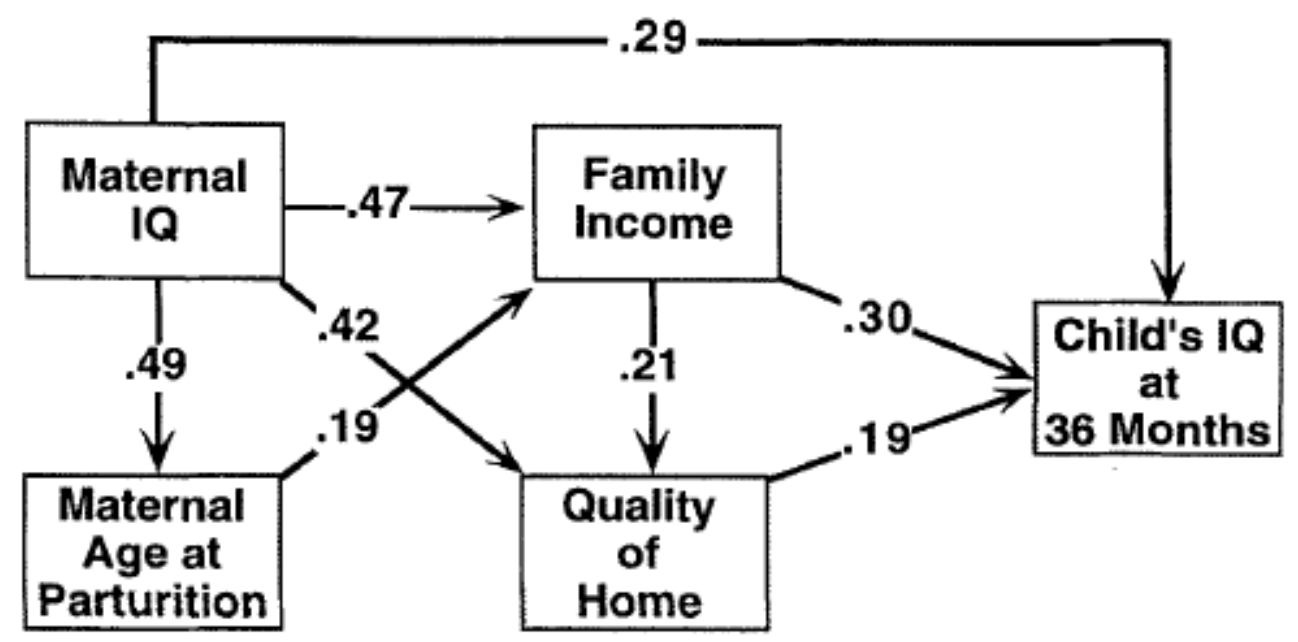

Total Effects:

Maternal IQ $=.53$

Maternal Age $=-.01$

Family Income $=.34$

Figure 1. Partial Standardized Regression Coefficients Linking Predictor Variables and Child IQ 
Child IQ scores were regressed on the predictor variables in the following order: (1) maternal IQ, (2) maternal age at parturition, (3) income (in thousands of dollars), and (4) HOME scores. Table 3 reports the R2 change as each variable was entered in the equation.

Maternal IQ accounted for 53\% of child IQ variance. Maternal age was not directly related to child IQ for this sample. Family income explained about $8 \%$ of child IQ variance, and quality of the home environment accounted for approximately $2 \%$ of child IQ variance after controlling for each of the preceding variables in the equation.

Statistically significant path coefficients linking the variables can be found in Figure 1. Approximately $45 \%$ of the total effect associated with maternal IQ was mediated by other variables in the equation. Of the total effect of maternal IQ on child IQ, family income explained $14 \%(t[451]=5.63, p<.005)$; home environment only $8 \%(t[451]=3.79$, $p<.005)$.

Income and maternal IQ were both directly associated with quality of the home environment. Maternal IQ also had an indirect effect mediated by income. Approximately $19 \%$ of the total effect of maternal IQ on quality of the home environment was mediated by family income, $t(451\}=4.11, p<.005$.

Although not directly associated with child IQ, maternal age at parturition was substantially correlated with maternal IQ $(r=.49)$. We explored this relationship further by dividing the sample into two groups based on maternal age. Teen mothers (18 years or less at parturition; $n=64)$ had an approximate mean IQ of $80(S D=12.2)$. The approximate mean IQ for the adult mothers was $88(n=389 ; S D=20.2), t(451\}=5.56, p<.00$.

The correlation of maternal age with child IQ was mediated by family income. As maternal age increased, family income tended to increase, producing a small $(b=.06)$ but statistically significant influence on child IQ, $t(451\}=3.78, p<.005$. The mediated effect almost exactly balanced the direct effect of maternal age on child IQ (total effect of maternal age $=-.01)$

Although maternal IQ was directly associated with total HOME scores, the mediated influence of home environment on the relationship between maternal and child IQs was quite small (8\%; Figure I). In view of this consideration, it is highly unlikely that any specific aspect of the home environment might be uniquely implicated in a major way.

\section{DISCUSSION}

Although there is substantial and growing research literature on long-term consequences of LBW on cognitive development, along with analyses of risk factors that distinguish between LBW and NBW children, the results of this study apply to a large sample of premature LBW children. Evidence now suggests that variables influencing developmental status of poor NBW children are different in type and/or degree than those affecting outcomes of poor LBW children, and that LBW children of less intellectually competent mothers who are also poor are at further relative increased risk for many compromised health outcomes (McGauhey, et al., 1991; Starfield, 1992). 
Unlike NBW children living in a high-risk social environment there are very few protective influences for similarly situated LBW children. The strategy used here is different from most other studies in that little is known about how these outcomes are manifested within groups of children already at LBW. Results and conclusions reported here are not intended to generalize across the entire birth-weight spectrum, but rather to examine how important variables identified in other studies impact cognitive outcome of infants already at elevated risk for poor health sequelae by the biological circumstances of premature LBW.

From this analysis the variable that stands out as the major contributor to child IQ among premature LBW children is maternal IQ, accounting for $53 \%$ of the variance. Family income explained $8 \%$ of child IQ variance. This outcome can be clearly seen in Table 3 where the $R 2$ change was most conspicuously influenced by these variables. The R2 change for home environment was also statistically significant, but the net contribution was very small.

These results have implications, not necessarily encouraging, for intervention programs for intellectually at-risk premature LBW children. Although some have maintained that cognitive intervention programs should be broadly targeted (e.g., Scott \& Carren, 1987), a more realistic or practical alternative is to devise empirically established interventions based on group-specific risk profiles (Brooks-Gunn, Gross, Kraemer, Spiker \& Shapero, 1992; Guralnick, 1991; Smith, Ulvund, \& Lindeman, 1994).

Candidates for interventions designed to promote cognitive development should be identified on the basis of the extent to which particular population-specific risk variables are implicated, with intervention focused on those conditions that are reasonably modifiable. Analyses such as this and those others have performed (e.g., Bendersky \& Lewis, 1994; Brooks-Gunn, Gross, Kraemer, Spiker, \& Shapiro, 1992) can be used for risk assessments that have reasonable sensitivity and specificity.

Results of our analyses go beyond confirming the well-established correlation between maternal and child intelligence. These analyses represent a critical step in the process of understanding how maternal IQ influences child IQ among LBW children. In this regard, our results can be viewed in connection with those reported by Bradley et al. (1993) who also found that quality of the home environment mediates effects of maternal IQ among this group of compromised children. But we add to this picture by showing that family income is a somewhat more potent mediator than home environment on effects of maternal IQ. We must acknowledge that although income was shown to make an important contribution to child IQ in the overall sample, regional differences and family structure undoubtedly affect how income is consumed. Nevertheless, in view of the relatively small magnitude of effect observed and because of the nature of the data base (i.e., eight geographic sites), adjustments were not made for locality or family size.

Despite the demonstration of mediated effects, most of the maternal IQ influence on child IQ for this group of premature LBW children was not mediated by any of the variables examined in this analysis. After controlling for age at parturition, income, and quality of the home environment, maternal IQ still accounted for approximately $29 \%$ of child IQ variance-a large effect size compared with other variables in the equation. The extent to which this value is a function of biological, psychological and/or socioeconomic mediators not included in the present analysis remains to be determined. But the point to be emphasized is that any intervention must directly take into account maternal competence, 
recognizing that low maternal intelligence restricts the range of intervention options. Maternal IQ is a critical and potent variable that must be included in any multivariate model exploring variables that might be modified to enhance cognitive development of premature LBW children. Interventions should focus on those factors that can explain variance that remains beyond direct effects of maternal IQ.

These analyses also allowed us to examine effects of maternal IQ, maternal age at parturition, and family income on quality of the home environment. Maternal IQ had a direct influence on home environment as well as an indirect effect mediated by family income. Another study involving some of the same subjects, but controlling for site and race, showed that poverty and maternal IQ had major and independent effects on HOME scores (Watson, Kirby, Kelleher, \& Bradley, 1996). Equally important, however, was our finding that the direct impact of maternal IQ on the home environment was larger than the mediated effect, and much larger than the direct effect of income on the home environment. Home environments of mothers with diminished intelligence are, in general, less congenial to intellectual development than homes of more intellectually competent mothers-a conclusion that has come to be widely accepted as a given. However, data presented here may raise questions as to effectiveness of manipulations designed to enhance home environment when the mother is intellectually limited.

For instance, a longitudinal study of infants judged to be at increased risk for developmental delay owing to economic or social disadvantage (mothers' mean IQ was 87) showed that an intensive, comprehensive, and long-term home-based education program had no effect on child cognitive outcome (Wasik, Ramey, Bryant, \& Sparling, 1990). Furthermore, home visitation did not affect HOME scores. In another study the failure to find an intervention effect on child IQ was nevertheless accompanied by evidence that the parent training improved the quality of the home environment (Barrera, Rosenbaum, \& Cunningham, 1986). A review of six "premier" two-generation family-focused support programs revealed only short-term impact on parents and very weak and transient effects on children (St. Pierre, Layzer, \& Barnes, 1995). Taking all these findings at face value, along with those reported here, we may conclude that interventions do not always affect HOME scores, and even when they do, influence on child IQ is minimal. Furthermore, whatever impact home environment has on child behavior diminishes over time as other social factors, such as school, exert increasingly greater influence.

Our results suggest that cause and effect have been confused in some previous studies. After controlling for maternal IQ, not much child IQ variance was left over for HOME scores to explain. A one-size-fits-all approach, no matter how intense, is unlikely to be effective in attempting to forestall adverse developmental outcomes among LBW infants (Baumeister \& Bacharach, 1996). Standard interventions based on altering the home environment to facilitate cognitive development of premature LBW children are weak at best, and probably ineffective for those at greatest risk.

We do not suggest that efforts to improve the home environment should be abandoned. We do assert that standardized HOME measures may be insensitive to significant parent-child interactions. Perhaps direct observation studies might be useful to identify specific characteristics that distinguish the learning environment in the homes of low IQ mothers from those in the homes of more intellectually capable mothers. Information of this nature might be used to develop more effective parenting skill intervention programs. 
These results did not yield a direct connection between maternal age at parturition and child IQ, although it is commonly assumed that mothers at extremes of reproductive age are at greater risk for poor pregnancy outcome (Fraser, Brockert, \& Ward, 1995). In this study the direct effect of maternal age on child IQ was not statistically significant, despite a significant positive zero-order correlation. After controlling for other variables, maternal age was negatively correlated with child IQ. The mediated effect, which was in the opposite direction, cancelled out whatever positive correlation there might have been, suggesting that reported correlations between maternal age at parturition and child IQ may be due to income rather than biological factors associated with childhood pregnancy. Again, it should be emphasized that these results apply to babies born small and prematurely, not to the full birth range.

Numerous studies have repeatedly shown that poverty is strongly associated with increased rates of LBW. In turn, low income is certainly associated with developmental delay, suggesting that children conceived and reared in suboptimal environments are subjected to a form of double jeopardy. Poverty has been linked to other more specific factors including individual behaviors, nutritional status, access to health care, lower educational attainment, and race among others. Yet it is not entirely clear how low socioeconomic status (here as defined by income) leads to increased reproductive risk (Hughes \& Simpson, 1995; Baumeister, et al., 1993). SES is a distal and composite variable that exerts developmental influence indirectly through such factors as access to social and medical services, lifestyle, and stress. The connection between poverty and poor developmental outcome is neither certain, decisive, nor direct. Most poor LBW babies are not, in the long run, seriously compromised intellectually. This is a matter of relative risks.

One important characteristic of the IHDP data is the wide range of family incomes represented in the sample. Although a substantial number of poor mothers were enrolled in the study, average family income was well above the poverty line. Some of the most notable long-term programs designed to improve cognitive development among children at risk, such as the Carolina Abecedarian Project (Ramey \& Campbell, 1984), understandably have deliberately focused on poor families. Nevertheless, such a strategy obviously restricts variance associated with income, thereby reducing opportunity to identify important correlates of income that might influence intellectual development. In the present study the direct of income on IQ among premature LBW children was significant, but not substantial.

Race is another variable that has been consistently implicated in outcomes associated with LBW. However, racial effects appear to be substantially mediated by variables included in the equations used here (Brooks-Gunn, et al., 1996). Some research has shown that the interval between pregnancies is shorter for black than for white women (Rawlings, Rawlings, \& Reed, 1995). Brief inter-pregnancy spacings (and, therefore, more children) may comprise maternal health, maternal-infant interactions, and financial resources. Results from this study show that maternal IQ and, to a lessor extent, income are predictive of 3-year IQs among LBW children. We conclude that pathways from poverty to poor health differ among subgroups, and that these are enduring differences. As Bendersky and Lewis (1994) showed in their analysis of environmental and biological risk factors among LBW infants, family risks exert a powerful influence on development over the first year of life. But they also observed that these effects are strongly mediated by individual characteristics, particularly biological status variables. 
Socioeconomic characteristics modify risks associated with prematurity. Protective factors include high parental intelligence and employment rates, family culture characterized by cohesion and the presence of at least one caring adult, and external supports (Garmezy, 1991). LBW children in a high-risk social environment do not have the same protective factors as NBW children-in fact, in one study none could be identified (McGauhey, et al., 1991). A problem is that while risk mechanisms tend to be direct, protective influences function indirectly by interacting with and modifying risk conditions (Rutter, 1987).

In this case, we have found that maternal IQ has both direct (genetic) and indirect effects mediated through income and, to a much lesser extent, the shared home environment. Those pathways may afford an opportunity for interventions to ameliorate or buffer some effects of premature LBW. In order to cushion the impact of biological and social risks, much more attention should be directed at those conditions directly related to income disparities including nutritional aspects, child care, job training, access to health care especially for chronic medical conditions (for both mothers and children), overcrowding, maternal stress, family support systems, and family planning-particularly spacing of pregnancies (Baumeister, et al., 1993; Brooks-Gunn, et al., 1996; McGauhey, et al., 1991; Rawlings, et al.,1995). Mandated provisions under Medicaid-including the Early Periodic Screening, Diagnosis, and Treatment Program-should be rigorously enforced because participation rates have been uniformly low across the states (Baumeister, et al., 1993).

Nevertheless even under the most optimal conditions, we expect that improved cognitive outcomes for many premature LBW children of poor and less intelligent mothers will still be marginal. It is one matter to know something of the nature of protective influences; quite another to put them into place. After failing to identify any long-term effects of an intervention program involving normal-weight and LBW infants of teenage mothers, Stone, Bendell, and Field (1988) suggested that stresses associated with poverty are overwhelming. They further warned of "intervention-dependence" in which impoverished mothers may be placed at relative disadvantage when left to their own.

Despite some exceptions (e.g., Rauh, Nurcombe, Achenbach, \& Howell, 1990), the generalization can be made that most efforts to produce significant and enduring cognitive improvements among these children through early infant stimulation (Wolke, 1991) or through family intervention and preschool center-based education (McCarton, BrooksGunn, Wallace, et al., 1997) have not been notably successful. In our view, much more emphasis should be directed at preventing serious premature LBW, particularly among poor women with below average intelligence (Baumeister \& Bacharach, 1996).

\section{NOTES}

1. R. T. Gross et al. Infant Health and Development Program (IHDP): Enhancing the outcomes of low birth weight, premature infants in the United States, 1985-1988 [Computer file]. Stanford, CA: Ruth T. Gross et al. (producers), 1990. Ann Arbor. MI: Inter-university Consortium for Political and Social Research (distributor), 1992.

2. These values were originally obtained by category. Following the procedure reported by Duncan, Brooks-Gunn and Klebanov (1994) we converted the values to dollar amounts corresponding to the mid-points of each category. 


\section{REFERENCES}

Alberman, E. (1994). Low birth weight and prematurity. In I. B. Pless (Ed.), The epidemiology of childhood disorders. (pp. 49-65). New York: Oxford University Press.

Alwin, D. F., \& Hauser, R. M. (1975). The decomposition of effects in path analysis. American Sociological Review. 40. 37-47.

Barrera, M. E., Rosenbaum, P. L., \& Cunningham, C. E. (1986). Early home intervention with low-birth-weight infants and their parents. Child Development. 57, 20-33.

Baumeister, A. A., \& Bacharach, V. R. (1996). A critical analysis of the Infant Health and Development Program. Intelligence, 23, 79-103.

Baumeister, A. A., Kupstas, F. D., \& Woodley-Zanthos, P. (1993). The new morbidity: Recommendations for action and an up-da/ ed guide to state planning for the prevention of mental retardation and related disabilities associated with socioeconomic conditions. Washington, D. C.: U. S. Department of Health and Human Services, President's Committee on Mental Retardation.

Bendersky, M., \& Lewis, M. (1994). Environmental risk, biological risk, and developmental outcome. Developmental Psychology, 3D, 484-494.

Birch, H. C., \& Gussow, 1. D. (1970). Disadvantaged children: Health, nutrition, and school failure. New York: Harcourt, Brace, and World.

Bradley, R., Caldwell, B., \& Rock, S. (1990). A system for describing elements of the environment: Model for assessing the home environments of developing children. Early Education and Development, 1, 237-265.

Bradley, R. H., \& Casey, P. H. (1992). Family environment and behavioral development oflowbirthweight children. Developmental Medicine and Child Neurology, 34, 822-832.

Bradley, R. H., Whiteside, L., Caldwell, B. M., Casey, P. H., Kelleher, K., Pope, S., Swanson, M., \& Barrett, K. (1993). Maternal IQ, the home environment, and child IQ in low birthweight, premature children.International Journal of Behavioral Development, 16, 61-74.

Breslau, N., DelDotto, 1. E., Brown, G. G., Kumar, S., Ezhuthachan, S., Hufnagle, K. G., \& Peterson, E. L. (1994). A gradient relationship between low birth weight and IQ at age 6 years. Archives of Adolescent Medicine, 148, 377-383.

Brofenbrenner, U. (1977). Toward an experimental ecology of human development. American Psychologist, 32, 513-531.

Brooks-Gunn, 1., \& Benasich, A. A. (1992). Mediating Variables. In R. T. Gross et al. (Eds.), Enhancing the outcomes of low birth weight, premature infants in the United States Vol I., (pp. 4-30 to 4-33). Ann Arbor: Inter-university Consortium for Political and Social Research [distributor]. 
Brooks-Gunn, J., Gross, R. T., Kraemer, H. C., Spiker, D., \& Shapiro, S. (1992). Enhancing the cognitive outcomes oflow birth weight, premature infants: For whom is the intervention most effective? Pediatrics, 89, 1209-1215.

Brooks-Gunn, 1., Klebanov, P. K., \& Duncan, G. 1. (1996). Ethnic differences in children's intelligence test scores: Role of economic deprivation, home environment, and maternal characteristics. Child Development, 67, 396-408.

Brooks-Gunn, 1., McCarton, C. M., Casey, P. H., McCormick, M. c., Bauer, C. R., Berbaum, 1. C., Tyson, I., Swanson, M., Bennett, F. C., Scott, D. T., Tonascia, I., \& Meinert, C. L. (1994). Early intervention in low birthweight premature infants. Journal of the American Medical Association, 272, 1257-1262.

Caldwell, B. M., \& Bradley, R. H. (1984). Home observationfor measurement of the environment. Little Rock: University of Arkansas at Little Rock.

Cohen, J., \& Cohen, P. (1983). Applied multiple regression/correlation analysis for the behavioral sciences, 2nd ed. Hillsdale, NI: Lawrence Erlbaum.

Drillien, C. M. (1964). The growth and development of the prematurely born infant. Baltimore: Williams \& Wilkins.

Duncan, G. I., Brooks-Gunn, I., \& Klebanov, P. K. (1994). Economic deprivation and early childhood development. Child Development, 65, 296-318.

Emanuel, I., Filaki, H., Alberman, E., \& Evans, S. I. W. (1992). Intergenerational studies of human birth weight from the 1958 birth cohort. I. Evidence for a mulitgenerational effect. British Journal of Obstetrics and Gynecology, 99, 67-74.

Escobar, G. H., Littenberg, B., \& Petitte, D. B. (1991). Outcome among surviving very low birth weight infants: A meta-analysis. Archives of Disease in Childhood, 66, 204-211.

Feldman, M. A., \& Walton-Allen, N. (1997). Effects of maternal mental retardation and poverty on intellectual, academic, and behavioral status of school-age children. American Journal on Mental Retardation, 101, 352-364.

Fraser, A. M., Brockert, I. E., \& Ward, R. H. (1995). Association of young maternal age with adverse reproductive outcomes. The New England Journal of Medicine, 332, 1113-111.

Garbino, J. (1991). The human ecology of human risk. In S. J. Meissels \& I. P. Shonkoff (Eds.), Handbook of early intervention. New York: Cambridge University Press.

Garmezy, N. (1991). Resiliency and vulnerability to adverse developmental outcomes associated with poverty. American Behavioral Scientist, 34, 416-430.

Gross, R. T., Spiker, D., \& Haynes, C. W. (Eds.) (1997). Helping low birth weight. premature babies: The Infant Health and Development Program. Stanford. CA: Stanford University Press.

Guralnick, M. 1. (1991). The next decade of research on effectiveness of early intervention. Exceptional Child. 58,174-183. 
Hack, M., Klein, N. K., \& Taylor, H. G. (1995). Long-tenn developmental outcomes of low birth weight infants. The Future of Children, 5, 176-196.

Hardy, J. B., \& Mellits, E. D. (1977). Relationship of low birth weight to maternal characteristics of age, parity, education, and body size. In D. M. Reed \& F. J. Stanley (Eds.). The epidemiology o/prematurity. (pp.I 05-125). Baltimore: Urban \& Schwarzenberg.

Hughes, D., \& Simpson, L. (1995). The role of social change in preventing mental retardation. The Future o/Children, 5,87-102.

Infant Health and Development Program. (1990). Enhancing the outcomes of low birth weight premature infants: A multisite, randomized trial. Journal of the American Medical Association, 263, 3035-3042.

Lee, H., \& Barratt, M. S. (1993). Cognitive development of pretenn low birth weight children at 5 to 8 years old. Development and Behavioral Pediatrics, 14,242-249.

Liaw, F., \& Brooks-Gunn, J. (1993). Patterns of low-birth-weight children's cognitive development. Developmental Psychology, 29, 1024-1035.

McCarton, C. M., Brooks-Gunn, J., Wallace, I. F., Bauer, C. R, Bennett, F. C., Bernbaum, J. C., Broyles, S., Casey, P. H., McConnick, M. C., Scott, D. T., Tyson, J., Tonascia, J., Meinert, C. L.; for the Infant Health and Development Program Research Group. (1997). Results at age 8 years of early intervention for low birth-weight premature infants. Journal of the American Medical Association, 277, 126-132.

McCorkmick, M. C., McCarton, c., Tonascia, 1., \& Brooks-Gunn, 1. (1993). Early educational intervention for very low birth weight infants: Results from the Infant Health and Development Program. Journal of Pediatrics, 123, 527-533.

McGauhey, P. J., Starfield, B., Alexander, c., and Ensminger, M. E. (1991). Social environment and vulnerability of low birth weight children: A social-epidemiological perspective. Pediatrics, 88, 943-953.

Mervis, C. A., Decoufle, P., Murphy, C. C., \& Yeargin-Allsopp, M. (1995). Low birthweight and the risk for mental retardation later in childhood. Pediatric and Perinatal Epidemiology, 9, 455468.

Plomin, R, \& Bergeman, C. (1991). The nature of nurture: Genetic influences on "environmental" measures. Behavioral and Brain Sciences, 14, 373-427.

Ramey, C. T., \& Campbell, F. A. (1984). Preventive education for high-risk children: Cognitive consequences of the Carolina Abecedarian Project. American Journal of Mental Deficiency, 88, 515-523.

Ramey, C. T., \& McPhee, D. (1986). Developmental retardation: A systems theory perspective on risk and preventive intervention. In D. C. Farren \& 1. D. McKinney (Eds.), Risk in intellectual and psychological development (pp.61-81). Orlando, FL: Academic.

Ramey, C. T., \& Ramey, S. L. (1992). Effective early intervention. Mental Retardation, 30, 337345. 
Rauh, V. A., Nurcombe, B., Achenbach, T., \& Howell, C. (1990). The Mother-Infant Transaction Program: The content and implications of an intervention for the mothers of low birth weight infants. Clinics in Perinatology, 17, 31-45.

Rawlings, J. S., Rawlings, V. B., \& Reed, J. A. (1995). Prevalence of low birth weight and pretenn delivery in relation to the interval between pregnancies among white and black women. The New England Journal of Medicine, 332, 69-74.

Riccuiti, A. E., \& Scarrs, S. (1990). Interaction of early biological and family risk factors in predicting cognitive development. Journal of Applied Development Psychology, 11, 1-12.

Rutter, M. (1987). Psychosocial resilience and protective mechanisms. American Journal of Orthopsychiatry, 57, 316-331.

Rutter, M., \& Madge, N. (1976). Cycles of disadvantage: A review 0/ research. London: Heinemann.

Sameroff, A. J. (1983). Developmental systems: Contexts and evolution. In W. Kessen (Ed.), Handbook of child psychology: Vol. 1. History, theories, and methods (pp.238-294). New York: Wiley.

Scott, K. G., \& Carren, D. T. (1987). The epidemiology and prevention of mental retardation. American Psychologist, 42,801-804.

Siegel, L. S. (1982). Reproductive, perinatal, and environmental factors as predictors of the cognitive and language development of pretenn and full-tenn infants. Child Development, 53, 963-973.

Smith, L., Ulvund, S. E., \& Lindemann, R (1994). Very low birth weight infants «1500) at double risk. Journal of Developmental and Behavioral Pediatrics, 15, 7-13.

St. Pierre, R. G., Layzer, J. I., \& Barnes, H. V. (1995). Two-generation programs: Design, cost, and short-term effectiveness. The Future o/Children, 5(3),76-93.

Starfield, B. (1992). Effects of poverty on health status. Bulletin of the New York Academy of Medicine, 68, 17-24.

Stone, W. L., Bendell, D. R., \& Field, T. M. (1988). The impact of socioeconomic status on teenage mothers and children who received early intervention. Journal of Applied Developmental Psyclwlogy, 9, 391-408.

Thompson, R. 1., Goldstein, R. F., Oehler. J. M., Gustafso, K. E., Catlett, A. T . \& Brazy, J. E. (1994). Developmental outcome of very low birth weight infants as a function of biological risk and psychosocial risk. Developmental and Behavioral Pediatrics, 15, 232-238.

Wasik, B. H., Ramey, C. T., Bryant, D. M., \& Sparling, J. 1. (1990). A longitudinal study of two early intervention strategies: Project CARE. Child Development, 61, 1682-1696.

Watson, 1. E., Kirby, R. S., Kelleher, K. J., \& Bradley, R. H. (1996). Effects of poverty on home environment: An analysis of three-year outcome data for low birth weight premature infants. Journal of Pediatric Psychology, 21, 419-431. 
Willerman, L. (1979). Effects of families on intellectual development. American Psychologist, 34, 923-927.

Wilson, R. R. (1985). Risk and resilience in early mental development. Developmental Psychology, 21, 795-805.

Wolke, D. (1991). Annotation: Supporting the development of low birthweight infants. Journal of Child Psychology and Psychiatry, 32(5), 723-741. 